Escatologia à la cantonade

\title{
ESCATOLOGIA À LA CANTONADE: Althusser para alÉm de Derrida ${ }^{1}$
}

Vittorio Morfino ${ }^{2}$

RESUMO: O autor propõe um confronto entre Althusser e Derrida acerca da questão da temporalidade, focalizando a leitura que os dois autores fazem de Marx sub specie theatri. A partir desse confronto, emerge uma teoria da temporalidade althusseriana, a qual se encontra para além, quer da teleologia da tradição hegeliano-marxista, quer do messianismo sem Messias proposto por Derrida, em sua releitura benjaminiana de Marx. Nesse sentido, a escatologia em Althusser é pensável somente à la cantonade.

PALAVRAS-CHAVE: Tempo. História. Escatologia. Teleologia. Althusser. Derrida.

A leitura de Espectros de Marx provoca no estudioso de Marx uma reação que Derrida, em Marx and sons, retomando Spivak, definiu como proprietoriaß. Desembainhar as armas da filologia marxista para mostrar como na realidade Derrida constrói a sua fascinante leitura de um número de páginas do texto de Marx extremamente exíguo e sem qualquer contextualização: algumas páginas da parte da Ideologia alemã dedicada a refutar o Único de Stirner, a página inicial do Manifesto, as páginas introdutórias do 18 Brumário, algumas páginas da Contribuição à crítica da economia política, poucas páginas de um parágrafo, embora célebre, do Capital. Todavia, a reação "proprietorial", ou "prioprietorial", segundo a sugestão de Derrida, evita de fato o fascínio de um desafio teórico. Acusar Derrida de ignoratio elenchi ou discutir a interpretação das poucas páginas marxianas com acribia filológica significaria, em um certo sentido, demarcar as fronteiras de um campo disciplinar, vigiando as violações a elas. Mais interessante e produtivo, ao contrário, é aceitar o desafio de Derrida no terreno da teoria, e tentar comparar

1 Escatologia à la cantonade. Althusser oltre Derrida. Tradução de Márcio Bilharinho Naves.

${ }^{2}$ Vittorio Morfino é investigador na área de História da Filosofia na Universidade de Milano-Bicocca. É autor de Substantia sive Organismos (1997); Sulla violenza. Una lettura di Hegel (2000); Il tempo e l'occasione. L'incontro Spinoza Machiavelli (2002); Incursioni spinoziste (2002); Il tempo della moltitudine (2005) e Spinoza e il non contemporaneo (2009). Organizou as coletâneas Spinoza contro Leibniz (1994); La Spinoz̨a Renaissance nella Germania di fine Settecento (2000); L'abisso dell'unica sostanz̧a (2009), além das edições italianas dos últimos escritos de Louis Althusser (2000) e de Logica e teoria della scienza, de Jean Cavaillés (2006). É colaborador de Quaderni materialisti e de Décalages.

${ }^{3}$ DERRIDA, J. Marx \& sons In: Ghostly demarcations, introduced by M. Sprinker. Londres/Nova York: Verso, 1999, p. 222. 
MORFINO, $V$.

o seu Marx sub specie theatri com aquele apresentado por Althusser, exatamente trinta anos antes, em um artigo com o título "Il Piccolo, Bertolazzi e Brecht". Naturalmente, expor uma comparação entre a interpretação de Derrida e a de um achado fóssil dos anos sessenta, Louis Althusser, e precisamente em uma convenção derridiana, deve ter tido um pouco daquela mesma "adolescent perversity" "que Terry Eagleton criticou em Derrida, a propósito de Espectros de Marx, fazendo-o sorrir.

\section{A disjunção da temporalidade no Hamlet de Derrida}

"The time is out of joint" o mundo está de cabeça para baixo. Em Espectros de Marx, o leitor se encontra frente a uma surpreendente e genial operação filosófica, que consiste em procurar a vitalidade da tradição marxista, isto que não se pode nem se deve cancelar da herança de Marx, na materialidade de um texto teatral, talvez o mais famoso da tradição ocidental, o Hamlet de Shakespeare. Deve-se ler Marx a partir de Hamlet, através de Hamlet, no sentido daquela extraordinria expressão que declara o tempo out of joint.

Em "The time is out of joint" - escreve Derrida -,

[...] Time é umas vezes o tempo mesmo, a temporalidade do tempo, outras vezes o que a temporalidade torna possível (o tempo como história, o correr do tempo, o tempo em que vivemos, os dias de hoje, a época), outras vezes, por conseguinte, o mundo como ele vai, nosso mundo hoje, a atualidade [...]. Time: é o tempo, assim como é a história e também o mundo. ${ }^{6}$

"The time is out of joint". A invenção literária de Shakespeare produz um fosso entre as diversas tentativas de tradução. Derrida resenha algumas das mais importantes tentativas francesas: a tradução de Yves Bonnefoy, “[...] le temps est hors de ses gonds"; aquela de Jean Malaplate, “[...] le temps est détraqué"; aquela de Jules Derocquigny, “[...] le monde est à l'envers"; aquela, por fim, de André Gide, “[...] cette époque est déshonorée”. A tradução de Gide ativa, segundo Derrida, um sentido fundamental do inglês de Shakespeare, o sentido ético-político da expressão, "[...] a decadência moral ou a corrupção da cidade, o

\footnotetext{
${ }^{4}$ Ibid., p. 228.

${ }^{5}$ SHAKESPEARE, W. Hamlet, I, V, 188. In: The riverside Shakespeare. Boston: Houghton Mifflin Company, 1974, p. 1151.

${ }^{6}$ DERRIDA, J. Spectres de Marx. Paris: Galilée, 1993, p. 43. Tr. bras. de Anamaria Skinner. Rio de Janeiro: Relume-Dumará, 1994, p. 35.
} 
desregramento [déreglement] ou a perversão dos costumes"' . A expressão, portanto, deve ser lida em um duplo registro, ontológico e ético-político: "E se esse duplo registro condensasse seu enigma, exatamente, e potencializasse sua superpotência no que confere sua força inaudita à fala de Hamlet?

"The time is out of joint - $\mathrm{O}$ cursed spite. That ever I was born to set it right!"”. Hamlet amaldiçoa o destino que lhe atribuiu a tarefa de "fazer justiça [...] corrigir a história [à rendre justice et redresser l'bistoire], a tortuosidade da história"10. Derrida pensa a herança de Marx a partir dessa possibilidade aberta por Hamlet (propondo uma leitura análoga àquela heideggeriana do Spruch des Anaximanders), de uma disjunção que é ao mesmo tempo aquela do injusto e aquela "[...] que abre a dissimetria infinita da relação com o outro, isto é, o lugar para a justiça", entendida não como cálculo, mas como incalculabilidade do dom $^{11}$. O tempo de Hamlet, nos diz Derrida, é o próprio tempo do mundo, da história, da sua época. Dando um passo a mais: o tempo do ser é o tempo da consciência. E, todavia, a justiça não deve ser pensada como a prestação de contas, como o reajustamento ético-ontológico do tempo, mas como a vinda mesma do evento do qual a disjunção do tempo, do presente, é condição necessária. Exatamente nesse sentido da proposição shakespeariana, Derrida encontra a herança mais profunda do marxismo, para além do materialismo histórico e do dialético, para além da ideologia incorporada nos aparelhos de partido e nas internacionais operárias. Derrida chama o evento com o seu nome histórico: o messias.

Por conseguinte, a herança de Marx deve ser apreendida através da tragédia de Hamlet, não no sentido mais superficial, na teleologia inscrita em um tempo cuja estrutura ontológica está dominada pela exigência ético-política de uma justiça enfim reinstaurada: não, portanto, segundo a notória canção hegelo-marxista do fim da história. A herança de Marx, que «[...] não se pode nem deve apagar», está, ao contrário, toda «[...] na espera ou na chamada do que denominamos [surnommons] aqui, sem saber, o messiânico: a vinda do outro, a

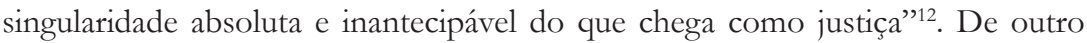
modo, a justiça "[...] corre o risco de se reduzir novamente a regras, normas ou representações jurídico-morais, num inevitável horizonte totalizador", enquanto o messianismo marxista proposto por Derrida implica "[...] um rejuntar sem

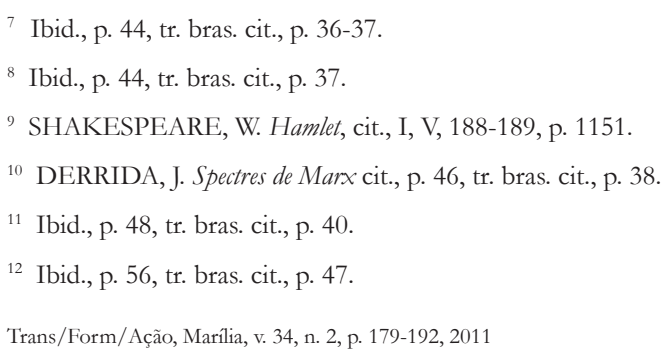


cônjuge [rejoindre sans conjoint], sem organização, sem partido, sem nação, sem Estado, sem propriedade"13.

Trata-se de pensar, conforme Derrida,

[...] uma extremidade messiânica, um eschaton cujo último acontecimento (ruptura imediata, interrupção inaudita, intepestividade da surpresa infinita, heterogeneidade sem realização) pudesse exceder, a cada momento, o termo final, de uma physis, como o trabalho, a produção e o telos de toda a história ${ }^{14}$.

A herança de Marx se encontraria, pois, não no discurso manifesto da tragédia shakespeariana (como toda tragédia clássica, intrinsecamente teleológica), mas na possibilidade latente de ler entre as suas linhas uma escatologia sem teleologia, a disjuntura ontológico-moral do tempo como ruptura "[...] em uma temporalidade geral ou em uma temporalidade histórica feita do encadeamento sucessivo de presentes idênticos a eles mesmos e deles mesmos contemporâneos"15, abertura à inserção do instante messiânico preparado por sinais que marcassem o testemunho de uma teologia em ação. Contra a ontoteo-arqueo-teleologia marxista, que neutraliza e bloqueia a historicidade, trata-se, segundo Derrida, de pensar

[...] uma outra historicidade, [...] uma outra abertura da eventualidade como historicidade que permitisse não mais renunciar a esta, mas, ao contrário, promover o acesso a um pensamento afirmador da promessa messiânica e emancipatória como promessa ${ }^{16}$.

\section{A estrutura dissimétrica da temporalidade em El nost Milan de} BERTOLAZZI

Ora, como foi dito, Espectros de Marx não permite qualquer penetração real na filosofia de Marx, apesar de os fragmentos de leitura que Derrida nos dá revelarem uma extraordinária capacidade de evocar a força das metáforas de que é entretecida a escritura marxista, o incrível talento de mostrar o resto de escritura que excede o querer dizer de Marx. Todavia, parece claro que Derrida entrevê a filosofia de Marx onde ela não está, nas Teses sobre o conceito de história e no Fragmento teológico-politico de Walter Benjamin; o materialismo histórico, o materialismo dialético, a ideologia dos partidos comunistas e das internacionais

13 Ibid., p. 58, tr. bras. cit., p. 48.

${ }^{14}$ Ibid., p. 68-69, tr. bras. cit., p. 57.

${ }^{15}$ Ibid., p. 119 , tr. bras. cit., p. 99.

${ }^{16}$ Ibid., p. 125-126, tr. bras. cit., p. 104. 
operárias, os países do socialismo real, a glória e os erros dessa história são liquidados com leveza pouco maior que a jornalística. E, no entanto, como eu disse, merece ser levado a sério em um outro nível, aquele da pura invenção filosófica: neste nível, torna-se produtivo o encontro com o pensamento de Louis Althusser. Não com a interpretação althusseriana de Marx a respeito da qual Derrida se declara explicitamente em oposição ${ }^{17}$, mas no nível da pura invenção conceitual, que também em Althusser se exercita na interpretação do teatro como ponto de observação privilegiado da realidade.

Não Shakespeare, mas Bertolazzi e Brecht. Em julho de 1962, Althusser assistiu à representação parisiense de El nost Milan, dirigida por Giorgio Strehler, e dedicou a ela um artigo, "Le 'Piccolo', Bertolazzi et Brecht (Notes sur un théâtre matérialiste)", que se torna em seguida o verdadeiro centro geométrico e teórico de $A$ favor de Marx.

Nos três atos18 de El nost Milan, Althusser vê representadas duas formas de temporalidade que se alternam na cena, sem qualquer nexo causal aparente: a temporalidade vazia da miséria da vida popular milanesa e a temporalidade plena, instantânea, do darma de um pai (El Peppon) que mata um jovem violento e prepotente (Carloeu, dito El Togasso), que bate e explora a jovem filha (Nina).

Os três atos apresentam segundo Althusser, “[...] a mesma estrutura e quase o mesmo conteúdo: a coexistência de um tempo vazio, longo e lento para viver, e de um tempo pleno, breve como um relâmpago»19. Entre essas duas formas de temporalidade, não há qualquer relação explícita:

Os personagens do tempo são como que estranhos aos personagens do relâmpago: eles thes deixam regularmente o lugar (como se a breve tempestade do drama os varresse da cena!) para aí retornar no ato seguinte, com outros aspectos, uma vez desaparecido esse instante estranho ao seu ritmo ${ }^{20}$.

O tempo vazio é uma «[...] crônica da existência miserável [...] de seres perfeitamente tipificados, perfeitamente anônimos e intersubstituíveis", é

\footnotetext{
17 “ $[\ldots]$ opomo-nos [...] às mais cuidadosas e mais modernas reinterpretações do marxismo por certos marxistas (particularmente franceses e próximos a Althusser) que antes acreditavam dever tentar dissociar o marximo de toda teleologia ou de toda escatologia messiânica (mas meu propósito é precisamente distinguir esta daquela)" (ibid., p. 147, tr. bras. cit., p. 123).

${ }^{18}$ Quatro no original, três na "reforma da estrutura da comédia" operada por Strehler.

${ }^{19}$ ALthusser, L. Le "Piccolo», Bertolazzi et Brecht (Notes sur un théâtre matérialiste). In: Pour Marx. 2. ed. Paris: La Découverte, 1996, p. 134, tr. bras. de D. Lindoso, 2. ed. Rio de Janeiro: Zahar, 1979, p. 117.

${ }^{20}$ Ibid., p. 134-135, tr. bras. cit., p. 117. 
um tempo "[...] de encontros esboçados, de propósitos cuidados, de disputas cortadas", um tempo que, do primeiro ao terceiro ato, "[...] tende para o silêncio e a imobilidade"; essa representação do tempo alude à existência de um fato, o subproletariado milanês do fim do século, que vive um

[...] tempo miserável, [...] em que nada passa, um tempo sem esperança nem futuro, $[\ldots]$ em que o próprio passado é fixado na repetição in cui lo stesso passato è come coagulato nella ripetizione $[. .$.$] o futuro é procurado apenas,$ $[\ldots]$ os gestos não têm sequência nem efeito, onde tudo se resume, pois, em algumas trocas ao rés da vida, da "vida cotidiana", [...] nas discussões e disputas que abortam ou que a consciência da sua inutilidade faz entrar no nada $[\ldots]^{21}$.

Em suma, conclui Althusser, “[...] um tempo parado onde ainda nada se passa que se assemelhe à História, um tempo vazio e suportado como vazio: o tempo mesmo da sua condição" 22 .

Para Althusser, é magistral a representação espacial que Strehler encena desse tempo da vida miserável das massas. No segundo ato, em particular, esse tempo se torna visível na estrutura espacial do amplo local de um refeitório popular (i cusinn economich):

Ao pé de um imenso muro meio arruinado e quase no limite de um forro inacessível, recoberto de inscrições regulamentares meio apagadas pelos anos, mas sempre legível, eis aí: duas imensas mesas longas, paralelas à rampa, uma no primeiro plano, a outra no segundo; atrás, contra o muro, uma barra de ferro delimitando o caminho de acesso ao refeitório. É por ali que virão os homens e as mulheres. À direita, uma alta parede perpendicular à linha das tábuas separa a sala das cozinhas. Dois guichês, um para o álcool, outro para a sopa. Por trás da parede, as cozinhas, as marmitas fumegando, o cozinheiro, imperturbável. Esse campo imenso das mesas paralelas, na sua nudez, esse fundo interminável de muro, compõem um lugar de uma austeridade e de uma vacuidade incríveis. Alguns homens estão sentados às mesas [...], vê-se que comem, ausentes, como se vêem todos os ausentes, os outros, que em Milão e em todas as grandes cidades do mundo executam os mesmos gestos sagrados [encher a colher, trazê-la à boca, deglutir], porque é toda a sua vida, e que nada lhes permite viver de outro modo o seu tempo. Não sei de outro modo que tenha figurado com tanta força na estrutura do espaço, na distribuição dos lugares e dos homens, na duração dos gestos elementares, a relação profunda dos homens no tempo que eles vivem ${ }^{23}$.

\footnotetext{
${ }^{21}$ Ibid., p. $135-136$, tr. bras. cit., p. 118.

${ }^{22}$ Ibid.

${ }^{23}$ Ibid., p. 136-137, tr. bras. cit., p. 119-120. Cf. as indicações cenográficas dadas por Bertolazzi (El nost Milan. In: BERTOLAZZI, C. El nost Milan e altre commedie. Torino: Einaudi, 1971, p. 41). 
Esse tempo da miséria e da repetição é suspenso pela irrupção de um outro tempo, o tempo do drama: a chegada de Nina faz aparecer "[...] rapidamente o esboço de uma 'história', a figura de um destino"24. Esse tempo que irrompe na cena no final dos atos é um tempo pleno, fechado, dramático, “[...] um tempo onde não se pode passar qualquer história"25, “[...] maduro no seu interior por uma força irresistível, e produzindo ele mesmo o seu conteúdo": é um tempo dialético no qual um telos guia a contradição que o atravessa26.

Qual é o sentido dessa sucessão na cena, da ordem de aparição alternada do tempo vazio e parado e do tempo pleno que o rasga, sem todavia afetar a sua lenta indiferença? Althusser dá uma resposta paradoxal: "[...] é justamente a ausência de relações que constitui a relação verdadeira". A obra adquire o seu sentido mais pleno e original quando chega "[...] a figurar e fazer viver essa ausência de relações"27. É ainda no segundo ato que Strehler torna visível, na cena, de modo mais potente essa ausência de relações:

[...] quando os homens deixaram o refeitório e onde só restam Nina, o pai e Togasso, alguma coisa de repente desapareceu: como se os convivas tivessem com eles levado todo o "décor" [...], o espaço mesmo dos muros e das mesas, a lógica e o sentido desses lugares; como se o único conflito substituísse esse espaço invisível e denso, irreversível, de uma única dimensão, aquele que o precipita em direção ao drama ${ }^{28}$.

O tempo fora do prumo, de cabeça para baixo, desonrado no drama de Shakespeare é o mesmo tempo do drama do pai de Nina: pouco importa que lá se trate do príncipe da Dinamarca e aqui de um velho homem do povo, a dialética que o atravessa é a mesma, assim como a vingança e a crueldade do destino nela inscritas. O sujeito dessa dialética é o mesmo e a mesma desconstrução derridiana não é que a deconstrução daquele tempo (porque que coisa é um eschaton sem um sujeito, ainda que somente pensado sob o signo da diferença e não da identidade?). Porém, na encenação de Strehler, um outro tempo desliza indiferente ao drama. Essa indiferença é, para Althusser, o sentido mais profundo da obra:

O paradoxo de El nost Milan é que a dialética aí desempenha por assim dizer lateralmente, às ocultas [latéralment, à la cantonade], alguma parte em um canto

${ }^{24}$ ALTHUSSER, L. Le «Piccolo», Bertolazzi et Brecht (Notes sur un théâtre matérialiste), cit., p. 132, tr. bras. cit., p. 115

${ }^{25}$ Ibid., p. 137 , tr. bras. cit., p. 120.

${ }^{26}$ Ibid., p. 137 , tr. bras. cit., p. 120

${ }^{27}$ Ibid., p. 138 , tr. bras. cit., p. 120.

${ }^{28}$ Ibid., p. 143, tr. bras. cit., p. 125. 
da cena e ao final dos atos: essa dialética, em vão a esperamos: os personagens não fazem caso dela. Ela toma o seu tempo e só chega no final, à noite $[\ldots]^{29}$.

The time is out of joint poderia ser traduzido hegelianamente por die Welt ist verkherte [o mundo está de cabeça para baixo]: o verbo alemão verkheren traduz, a meu ver, perfeitamente o sentido ao mesmo tempo ontológico e ético-político do inglês shakespeariano. Um tempo de cabeça para baixo é um tempo que inscreveu em si o percurso teleológico do seu fluir. Derrida evita a cada passo o risco de um tal resultado, uma filosofia do fim da história que aprisiona a historicidade, dom que supera a sucessão sempre igual dos presentes, no relato de uma história do Homem. Todavia, ele desconstrói aquele tempo, o tempo da dialética da consciência, sem perceber fora dele esse outro tempo, o cubo vazio do refeitório, da disposição dos lugares e dos gestos, que é indiferente ao tempo dialético e à sua desconstrução escatológica.

Althusser considera essencial a toda tentativa teatral de caráter materialista precisamente aquela estrutura dissymétrique e décentrée que opera em El nost Milan. Em algumas grandes obras de Brecht, como Mãe coragem e A vida de Galileu, funciona, segundo Althusser, a mesma estrutura latente que permite a crítica das ilusões da consciência “[...] pela realidade desconcertante que está em seu fundo":

\begin{abstract}
Assim, a guerra, na Mãe Coragem, face aos dramas pessoais da sua cegueira, às falsas urgências da sua avidez; assim no Galileu, essa história mais lenta do que a consciência impaciente do verdadeiro, essa história também desconcertante para uma consciência que jamais chega a "possuir-se" duravelmente sobre ela no tempo da sua curta vida ${ }^{30}$.
\end{abstract}

Nesse sentido, Brecht subverteu as regras do teatro clássico, no qual o personagem central reflete na consciência de si o sentido total da obra, no qual o tempo do mundo e seus eventos acompanham a dialética daquela consciência.

\title{
3. Temporalidade Plural
}

Tentemos agora avançar mais um passo. Foi dito que o sentido mais profundo da leitura strelehriana da obra de Bertolazzi repousa na ausência de relações entre o tempo da consciência e o tempo da vida das massas. Derrida, desconstruindo o tempo teleológico, permaneceria no fundo enredado nele, tomando-o como o único tempo. Em Althusser, não apenas a teleologia é à

${ }^{29}$ ALTHUSSER, L. L'objet du Capital. In: Lire le Capital. 3. ed. Paris: PUF, 1996, p. 280, tr. bras. de Nathanael Caixeiro. Rio de Janeiro: Zahar, 1979, p. 36.

${ }^{30}$ Ibid., p. 280-281, tr. bras. cit., p. 36-37. 
la cantonade, mas também a escatologia. Não messianismo sem messias (ou promessa messiânica sem messianismo, se se preferir), como escreve Derrida, mas messianismo à la cantonade, messianismo às margens, porém, não das margens em direção a um centro, antes, às margens de um centro que é indiferente em relação a ele, ou melhor, que não existe.

Mas, aquele outro tempo de que fala Althusser, o que é do ponto de vista teórico, fora da representação teatral? Em Ler o Capital, Althusser tinha tentado dar uma resposta naquele esboço de uma teoria do tempo histórico que talvez constitua o coração de toda a obra. O primeiro passo foi constituído pela crítica da representação hegeliana do tempo, fundada na continuidade homogênea $e$ na contemporaneidade ou categoria do presente histórico, as duas coordenadas pela Ideia, sucessão e simultaneidade, no seu aparecer sensível. Das duas, aquela de longe a mais importante é, de acordo com Althusser, a segunda. De fato, a categoria de contemporaneidade diz precisamente qual é a estrutura da existência histórica da totalidade social, cuja natureza espiritual assegura que cada parte seja pars totalis, em sentido leibniziano, e que, operando uma seção de essência dessa totalidade, se encontre em todos os níveis da sociedade ao mesmo tempo. Ora, a continuidade do tempo se funda precisamente na sucessão contínua desses horizontes contemporâneos, cuja unidade é garantida pela onipresença do conceito.

Portanto, "[...] elaborar o conceito marxista de tempo histórico a partir da concepção marxista da totalidade social" significa, em primeiro lugar, tomar distância da teoria hegeliana do tempo histórico. De fato, o todo social marxiano é

[...] um todo cuja unidade, longe de ser a unidade expressiva ou 'espiritual' do todo de Leibniz e Hegel, é constituído por certo tipo de complexidade, a unidade de um todo estruturado, comportando o que podemos chamar de níveis ou instâncias distintas e 'relativamente autônomas', que coexistem nessa unidade estrutural complexa, articulando-se uns com os outros segundo os modos de determinações específicas, determinadas em última instância pelo nível ou instância da economia'.

O todo, para Marx, é "[...] um todo orgânico hierarquizado", todo que decide exatamente sobre a hierarquia, o grau e o índice de eficácia entre os diversos níveis da sociedade, cuja temporalidade não pode ser pensada através da categoria hegeliana de contemporaneidade:

[...] a coexistência dos diferentes níveis estruturados: o econômico, o político, o ideológico, etc., portando da infraestrutura econômica, da superestrutura jurídica e política, das ideologias e formações teóricas (filosofia, ciências), não pode ser pensada na coexistência do presente hegeliano, desse presente 
MORFINO, $V$.

ideológico em que coincidem a presença temporal e a presença da essência com os seus fenômenos ${ }^{31}$.

Não somente um tempo contínuo e homogêneo “[...] não pode ser tomado como o tempo da história", mas não é possível nem ao menos pensar "[...] no mesmo tempo histórico o processo do desenvolvimento dos diferentes níveis do todo": todo nível tem de fato "[...] um tempo próprio relativamente autônomo dos demais níveis" ${ }^{\prime 2}$.

Derrida, que ensinava na École Normale no mesmo período do seminário sobre $O$ capital, não podia não conhecer essa teoria da temporalidade de Althusser. E, com efeito, em uma das entrevistas publicadas em Posições, encontramos uma breve passagem dedicada a ela, que nos dá a confirmação disso:

[...] toda a crítica, tão necessária do conceito "hegeliano" de história, e da noção de totalidade expressiva etc., feita por Althusser, visa a mostrar que não existe uma história única, uma história geral, mas histórias diferentes, em seu tipo, seu ritmo, seu modo de inscrição, histórias deslocodas, diferenciadas etc. [il n'y a pas une seule histoire, une bistoire générale mais des histoire différentes dans leur type, leur rythme, leur mode d'inscription, bistoires décalées, différenciées, etc. $]^{33}$

A cela - acrescenta Derrida - j'ai toujours souscrit. Derrida encontra em Althusser a sua mesma refutação de um esquema linear do desenvolvimento da presença expresso na Gramatologia. Não uma história, portanto, mas muitas histórias, assim sintetiza Derrida e concorda. Entretanto, na passagem sucessiva, marca uma distância:

Coloco um outro tipo de questão: a partir de qual núcleo semântico mínimo se chamariam ainda "histórias" esses tipos de histórias heterogêneas, irredutíveis etc.? Como determinar esse mínimo que eles deveriam ter em comum se não é por pura convenção ou por pura confusão que se lhes deve conferir o nome comum de história? [...] Tão logo coloquemos a questão da historicidade da história - e como evitá-lo se lidamos com um conceito pluralista ou heterogeneísta da história? -, somos tentados a responder por uma definição de essência, de quididade, a reconstituir um sistema de predicados essenciais, e somos levados a rearranjar o fundo semântico da tradição filosófica. Tradição filosófica que acaba sempre por compreender a historicidade precisamente em relação a um fundo ontológico. É preciso, então, não apenas perguntar-se qual é a "essência" da história, a historicidade da história, mas também a "história"

${ }^{31}$ Ibid., p. 283 , tr. bras. cit., p. 39.

${ }^{32}$ Ibid., p. 284 , tr. bras. cit., p. 39.

${ }^{33}$ DERRIDA, J. Positions. Paris: Les Editions de Minuit, 1972, p. 79, tr. bras. de Tomaz Tadeu da Silva. Belo Horizonte: Autêntica, 2001, p. 65. 
da "essência" em geral. E se quisermos marcar uma ruptura entre algum "novo conceito de história" e a questão da essência da história (como conceito que ela regula), a questão da história da essência e da história do conceito, enfim, da história do sentido do ser $[\ldots]^{34}$.

O risco, segundo Derrida, é a reapropriação metafísica do conceito de História. Esse caráter não está ligado somente à linearidade, para Derrida, mas “"...] a todo um sistema de implicações (teleologia, escatologia, acumulação relevante e interiorizante do sentido, um certo tipo de tradicionalidade, um certo conceito de continuidade)" ${ }^{\prime 35}$. Para o conceito de história, assim como para qualquer outro conceito, acrescenta Derrida, "[...] não se pode efetuar uma mutação simples e instantânea": "é preciso elaborar uma estratégia do trabalho textual que, a cada instante, tome de empréstimo uma palavra antiga à filosofia para imediatamente demarcá-la"36.

Ora, se retomamos Espectros de Marx, e especificamente a sua definição da temporalidade, isso resulta de todo insuficiente precisamente à luz do projeto apresentado em Posições:

[...] uma extremidade messiânica, um eschaton cujo último acontecimento (ruptura imediata, interrupção inaudita, intempestividade da surpresa infinita, heterogeneidade sem realização) pudesse exceder, a cada momento, o termo final, de uma physis, como o trabalho, a produção e o telos de toda a história.

Aqui não há afastamento da tradição, mas repetição. Repetição de uma longa tradição teológica que de Paulo leva até a Benjamin, do Deus que vem como um ladrão na noite. E se depois, para marcar a própria diferença em relação a essa tradição, Derrida escreve em Marx \& Sons que a "Messianicity" não deve ser reduzida a "[...] religious messianism of any stripe", mas deve, ao contrário, ser entendida como uma "[...] universal structure of experience" ${ }^{" 37}$, não faz mais que evidenciar um curto-circuito entre a Alteridade do Evento-Messias e a alteridade de cada evento histórico concreto singular, curto-circuito que tem ao menos o mérito de revelar-se o óbvio contraponto dessa alteridade: a consciência e a sua experiência. Não estamos, seguramente, à altura da radicalidade do projeto de Posições.

Se, ao contrário, retomamos o projeto althusseriano, descobrimos que não há apenas a afirmação de um tempo plural, como considera Derrida, mas também

${ }^{34}$ Ibid., p. $80-81$, tr. bras. cit., p. $65-66$.

${ }^{35}$ Ibid., p. 77 , tr. bras. cit., p. 64.

${ }^{36}$ Ibid., p. 80, tr. bras. cit., p. 66.

${ }^{37}$ DERRIDA, J. Marx \& sons, cit., p. 248. 
a teoria da articulação desses tempos e a tentativa de redefinir radicalmente todo aquele "sistema de implicações" do conceito de história (seja singular, seja plural) precisamente através dessa articulação.

Segundo Althusser, a cada formação social corresponde o tempo e a história do desenvolvimento das forças produtivas, das relações de produção, da superestrutura política, da filosofia, das produções estéticas. Cada uma dessas histórias peculiares é escandida conforme ritmos peculiares, e pode ser conhecida somente se se determina o conceito da especificidade da sua temporalidade, com o seu desenvolvimento contínuo, as suas revoluções, as suas rupturas. Não se trata de setores independentes, mas relativamente autônomos, autonomia relativa que é apenas fundada sobre um certo tipo de articulação do todo, sobre um certo tipo de dependência:

[...] a especificidade desses tempos e dessas histórias é portanto diferencial, dado que fundada nas relações diferenciais existentes no todo entre os diferentes níveis $[\ldots]$ não basta dizer, como o fazem alguns historiadores modernos que bá $\left[\begin{array}{lll}\text { il } & y & a\end{array}\right]$ periodizações diferentes segundo os diferentes tempos, que cada tempo tem seus ritmos, alguns lentos, outros longos, mas é preciso pensar essas diferenças de ritmos e de escansão em seus fundamentos, no tipo de articulação, de deslocamento e de torção que relaciona esses diferentes tempos entre ii $^{38}$.

De acordo com Althusser, Marx foi particularmente sensível a essa problemática: no Capital, ele mostra como o tempo da produção econômica não pode ser lido na continuidade do tempo da vida ou dos relógios; trata-se, ao contrário, de um tempo complexo e não linear, um tempo dos tempos que deve ser construído a partir da distribuição e da circulação. Tempo essencialmente invisível e ilegível, opaco, "[...] entrecuzamento complexo dos diferentes tempos, dos diferentes ritmos, rotações, etc.", tempo que pode ser exibido somente através do conceito e que, pois, deve ser construído. E Althusser sublinha como na construção desse conceito não têm qualquer utilidade as categorias de contínuo e descontínuo "[...] que resume o mistério vulgar de toda a história"; trata-se de construir categorias "infinitamente mais complexas, específics segundo o tipo de história em que ocorrem novas lógicas”39.

A contemporaneidade, o momento atual é, por conseguinte, um entrelaçamenteo diferencial dos tempos. O que ocorre, se se sobrepõe esse momento a um corte de essência?

A coexistência que se verifica no "corte de essência" - responde Althusser -

\footnotetext{
${ }^{38}$ ALTHUSSER, L. Ler o Capital, cit., p. 284-285, tr. bras. cit., p. 40 (com alteração feita por mim).

${ }^{39}$ Ibid., p. 289, tr. bras. cit., p. 44.
} 
[...] não revela qualquer essência onipresente, que seja o próprio presente de cada um dos "níveis". O corte que "vale" para determinado nível, seja político ou econômico - que portanto corresponda a um "corte de essência" para o político, por exemplo - não corresponde a nada de semelhante para os outros níveis, econômico, ideológico, estético, filosófico, científico - que vivem em outros tempos, e passam por outros cortes, outros ritmos e outras pontuações. A presença de um nível é, por assim dizer, a ausência de outro e essa coexistência de uma "presença" é apenas o efeito da estrutura do todo em sua descentração articulada ${ }^{40}$.

Uma formação social é, portanto, um entrelaçamento de diversos tempos dos quais é necessário pensar a defasagem e a torção produzidos pela articulação dos diferentes níveis da estrutura. O risco implícito nessa teoria da temporalidade consiste em pensar o corte de essência não de modo linear, mas em graus, pensando a ausência de um nível em relação à presença de outro como antecipação ou atraso. Se fizéssemos isso - escreve Althusser -

[...] cairíamos como acontece com frequência entre os melhores historiadores, na armadilha da ideologia da história, em que o avanço e o atraso não passam de variantes da continuidade de referência, e não efeitos da estrutura do todo ${ }^{41}$.

Para fazer isso, é necessário se livrar das evidências da história empírica e produzir o conceito de história. Se as diferentes temporalidades se referem a um mesmo tempo, cai-se na ideologia do tempo homogêneo:

Se não podemos efetuar na história esse "corte de essência", há de ser na unidade específica da estrutura complexa do todo que devemos pensar o conceito desses pretensos atrasos, avanços, sobrevivências, desigualdades de desenvolvimento que co-existem na estrutura do presente histórico real: o presente da conjuntura ${ }^{42}$.

Desse modo, para falar através das metáforas de "antecipação" e "atraso", ocorre pensar o lugar e a função daquela temporalidade diferencial no todo, através de um conceito de sincronia que, desvinculada do modelo estruturalista, identificase com a eternidade spinoziana: conhecimento da complexidade do real, por meio da produção dessa complexidade em nível conceitual, produção que traça a linha de demarcação entre o verdadeiro e o imaginário (linha de demarcação que a espectrologia de Derrida recusa firmemente traçar), entre a temporalidade simples e singular da imaginação e aquela complexa e plural da história.

\footnotetext{
${ }^{40}$ Ibid., p. 290, tr. bras. cit., p. 44.

${ }^{41}$ Ibid., p. 291, tr. bras. cit., p. 45.

${ }^{42}$ Ibid., p. 293, tr. bras. cit., p. 45. 
MORFINO, $V$.

Em Posiçoes, Derrida tinha afirmado que o discurso sobre a pluralidade dos tempos althusseriana só pode se verificar na forma do conceito e, assim, que ela termina por recair na metafísica. No entanto, aqui, talvez Derrida seja prisioneiro de uma concepção do tempo que gostaria de elidir, seja prisioneiro de uma epocalização da metafísica, no fundo linear e expressiva. Existe conceito também fora da metafísica, em Spinoza, por certo, mas também naquela tradição que em um escrito póstumo Althusser definirá como do materialismo do encontro: Lucrécio, Maquiavel e outros, ainda. É em companhia desses autores que Althusser pode dizer que, na história, não fala a voz de um logos, mas o inaudível e ilegível traço de uma estrutura de estruturas. E é sobretudo em companhia de Marx que Althusser pode chegar a pensar o conceito que lhe permite articular a pluralidade das histórias: o conceito de modo de produção e, especificamente, de modo de produção capitalista. Esse é o tempo do cubo vazio do refeitório, da disposição dos lugares e dos gestos, em relação aos quais toda teleologia e toda escatologia estão às margens, à la cantonade. Esse tempo é o objeto do Capital, a obra fundamental de Marx, que a escuridão interna de Espectros de Marx exclui do próprio campo de visão, ao constituí-lo ${ }^{43}$.

MORFINO, V. Ecatology à la cantonade: Althusser beyond Derrida. Trans/Form/Ação, Marília, v. 34, n.2, p. 179-192, 2011.

ABSTRACT: The article proposes a comparison between Althusser and Derrida on the question of temporality through the two Marx's reading sub specie theatri set by the two authors in Pour Marx and in Spectres de Marx. From this comparison emerges that the althusserian theory of temporality is beyond the teleology of the hegelo-marxist tradition, but also of the messianism without messiah that is at the core of the Derrida's interpretation of Marx strongly influenced by Benjamin. In this sense, in a provocative way, it can be said that in Althusser the escatology is à la cantonade.

KEYWORDS: Temporality. History. Escatology. Teleology. Althusser. Derrida.

Recebido em: 22 de março de 2011

Aprovado em: 13 de junho de 2011

${ }^{43}$ Sobre isso, escreve Macherey: "This enterprise of deconstruction, which draws Marx alongside his
ghosts, succeeds perfectly on the condition of filtering his inheritance to the point of retaining from
Capital only Part I Chapter 1: Marx without social classes, without the exploitation of labor, without
surplus-value, risks, in fact, no longer being anything but his own ghost" (MACHEREY, P. Marx
dematerialized, or the Spirit of Derrida. In: Ghostly demarcations, cit., p. 24). 